\title{
불교고고학의 성립과 발전을 위한 제언
}

흥 선 \| 문화재위원, 전 불교중앙박물관장

\section{1}

뵙게 되어 반갑습니다. 먼저 제가 이 자리에 서게 된 경위부터 말씀드리 는 것이 순서일 듯합니다. 멀리 해외에서 오신 분들은 모르셔도 국내의 학 자분들이나 참석자들께서는 퍽 의아하시리라 짐작됩니다. 고고학자도, 그렇 다고 고고학에 남다른 인연과 지대한 관심이 있는 것도 아닌 제가 이 자리 에 참석하여 전문가들을 상대로 고고학에 대해 무언가 발언을 하게 된 것이 다소 엉뚱하고 그다지 어울리지 않을 것이기 때문입니다. 그렇습니다. 저는 고고학자도, 고고학에 남다른 식견과 소양이 있는 사람도 아닙니다. 말하자 면 이 자리에 썩 어울리지 않는 사람입니다. 그런데도 무모하게 이 자리에 서게 된 것은 전적으로 유약한 저의 성격 탓입니다. 저는 깨 오랫동안 불교 계에 몸담아 왔고, 또 상당 기간 사찰 박물관에서 일하면서 고고학의 이웃사 촌쯤 되는 불교미술 분야에 관심을 표명해 온 사람입니다. 그렇다고는 해도 그것이 이 자리에 참석하여 감히 이러쿵저러쿵할 만한 구실은 전혀 되지 않 기 때문에, 당초 이번 학술세미나를 준비하는 쪽에서 참석을 요청했을 때 정중하되 단호하게 거절해야 마땅했을 것입니다. 그런데 인정에 쉽게 끌리 고 매사에 끊고 맺지 못하는 우유부단함 때문에 감당하기 어려운 일임을 뺀 히 알면서도 덜컥 수락하는 실수를 저지르고 말았습니다. 
저간의 사정이 이러하니, 오늘 이 자리에서 제가 여러분들에게 참신하고 유익한, 깊이 있고 전문적인 말씀을 드릴 수 없음은 자명합니다. 그저 어깨 너머로 넘겨다보아 학계 사정을 조금 아는 관찰자로서, 또 평범한 교양을 지 닌 한 시민으로서 이미 여러분 모두가 충분히 유념하고 있을 상식적이고 기 본적인 몇 가지 사항들을 다시 끄집어내어 언급하는데 지나지 않을 것입니 다. 따라서 국외자로서 제가 드리는 소견이 대수로울 리 없고 큰 도움은 안 되겠지만, 여러분의 주의를 다시 한번 환기시키는 구실이라도 할 수 있다면 더없이 다행이겠습니다.

\section{2}

외국의 사정이 어떤지는 잘 모르겠습니다만, 저는 평소 우리 학계 일각에 참으로 이해하기 어려운 일이 적지 않다고 생각해 오고 있습니다. 그 대표 적인 사례 가운데 하나가 학문의 세계와는 도무지 어울릴 것 같지 않은 '파 벌주의'가 상당히 견고하게 자리잡고 있다는 것입니다. 이게 무슨 말인가 하 시겠습니다만, 제가 속사정을 조금은 알고 있는 한 인문학 분야에서는 틀림 없이 그런 모습을 살펴 알 수 있습니다. 고고학과 가깝다면 꽤 가까운 이 분 야에 종사하는 연구자들은 대체로 세 그룹으로 나누어집니다. 그 기준은 출 신 학교입니다. D대, H대, S대, 이 세 학교의 특정 학과 출신자들은 자의반 타의반으로 선후배 동창들로 이루어진 한 그룹에 속하게 됩니다. 그리고는 서로 밀어주고 끌어주며 학문적 활동을 하고, 사회적 관계도 유지합니다. 이 들 그룹의 중심에, 그리고 가장 앞자리에 그들을 지도하여 배출한 교수님들 이 있습니다. 사계의 중진 혹은 원로인 이 교수님들은 각각의 그룹에서 대 단한 권능을 지니고 있으며 막강한 지도력과 영향력을 행사합니다. 한마디 로 그것은 학문적 동료관계가 아니라 종속관계이며 상하관계라고 할 수 있 습니다. 제자 입장에서 스승의 학설을 부정하거나 비판하는 것은 거의 가능 하지 않은, 좀체로 상상하기도 어려운 일에 속합니다. 학회나 학술대회 같은 
학문적 토론의 장에서도 비판과 공격의 대상은 자기 그룹에 속하지 않은 연 구자와 그들의 논문이지 같은 그룹에 속한 동료와 선후배, 스승이 논쟁의 상 대가 되는 경우는 거의 없습니다. 조금은 우스꽝스럽기도 하고, 씁쓸하기도 한 이런 모습이 이 분야 전문 종사자들이 모인 토론 마당에서 쉽게 볼 수 있 는 풍경입니다.

저는 학계 일각의 이런 모습이 낮설기도 하고 영 익숙해지지 않습니다. 어떻게 학풍 혹은 학문적 경향의 차이가 아니라 오로지 출신 학교에 따라 편을 가르듯 소속 집단을 나누고 거기에 속해 학문적 활동을 할 수 있는지 납득이 되지 않습니다. 제 눈에는 그것이 학파가 아님은 물론이거니와, 오히 려 이익집단에 가까워 보이고 조금 심하게 말하면 무슨 패거리 같습니다. 모름지기 학문이라면, 또 학문을 하는 학자라면 독립과 자유의 바탕 위에서 창의적인 세계를 열어가야 할 텐데, 구성원 사이에 격의 없는 비판과 토론조 차 허용되지 않고 주어진 틀 안에서만 사고하고 표현해야 한다면, 그 안에서 어떻게 학문적 발전이 가능한지 잘 모르겠습니다. 종교집단이라면 모를까, 스승의 학설에 이의를 제기할 수 없는 분위기나 그런 상황을 요구 혹은 묵 인하고 있는 스승이 존재한다는 사실도 저로서는 매우 비학문적으로 여겨집 니다. 내용에 관계없이 미리 정해진 피아의 구분에 따라 저쪽이면 공격하고 이쪽이면 감싸는 태도가 과연 얼마나 학문적일까 싶기도 합니다.

고고학계는 이와 같거나 비슷한 파벌주의로부터 완전히 자유롭습니까? 저의 이런 질문이 불필요한 기우이고 쓸모없는 노파심이기를 바랍니다만, 만일 그렇지 않다면 학문적 활동에 앞서 그런 요소들을 제거하고 뿌리내리 지 못하도록 관련된 분들 모두의 노력이 선행되어야 하지 않을까 싶습니다. 저는 분야에 상관없이 학문은, 예술과 마찬가지로, 기본적으로 자유로운 영 혼의 독자적인 지적 활동이라고 생각합니다. 그래서 상호 협력이 필요한 공 동연구 따위가 아니라면 같은 분야 연구자들이 굳이 '끈끈한' 인간관계로 맺 어질 이유가 없다고 봅니다. 불교고고학의 가능성을 타진하고 전망해보는 
오늘 같은 자리에서 한번쯤 점검해 보아야 하지 않을까 싶어서 진부하지만 엄연한 현실인 학계 일부의 파벌주의 문제를 제기해 보았습니다.

방금 말씀드린 분야의 끼리끼리 뭉치기를 좋아하는 연구자들의 학문 활 동을 곁눈질하면서 또 한 가지 제가 발견한 것이 있습니다. 자료를 독점하 려는 경향 혹은 선점의 이득을 과도하게 누리려는 경향이 지나치게 강하다 는 것입니다. 빠른 이해를 돕기 위해 예를 들어 설명해 보겠습니다. 여기 새 롭게 발견된 고대 금석문이 있습니다. 그렇다면 아마도 발견자는 기초적인 정보를 정리하여 머지않은 시기에 발견 사실을 학계에 보고할 것입니다. 그 러면 또 이 금석문에 관심을 갖는 누구라도 그것을 직접 관찰하고, 해석하 고, 평가하여 각자 나름대로 자기 주장을 펼칠 수 있습니다. 다시 말해 자료 는 만인이 공유하면서 학문적인 경쟁은 그것을 바라보는 시각, 해석과 평가, 그에 바탕을 둔 학설의 구성 등을 중심으로 이루어집니다. 그런데 만일 처 음 금석문을 발견한 사람이 그런 사실을 공개하지 않고 자료를 독점하여 혼 자만 연구에 임한다거나 자신의 연구 결과를 발표한 뒤에야 공개를 한다면 그것을 공정하다고 여길 사람은 별로 없을 것입니다. 유감스럽게도 이렇게 자료에 남보다 먼저 접근했다는 이유 하나만으로 그것을 독점하거나 선점하 여 과도한 프리미엄을 누리고, 그것을 학문적 경쟁이라고 간주하며, 다른 사 람들은 그것을 당연한 기득권인 양 수용하고 묵인하는 관행이 우리 학계 일 각에 자리잡고 있습니다. 이 점도 불교고고학을 논하는 관계자 여러분들께 서 반면교사로 삼지 않아도 되는지 어떤지, 파벌주의 문제와 더불어 한번쯤 생각해 보시면 좋겠습니다.

다음으로 생각해 보고 싶은 것이 소통과 교양의 문제입니다. 요즈음은 서 로 다른 학문 분야 사이에 유행처럼 소통과 통섭이 이야기되는 시대입니다. 학문 분야가 지나치게 세분화되다 보니 깊이는 보되 넓게는 보지 못한다는 반성에서 출발한 현상입니다. 당연한 일이고 바람직한 상황 전개라고 생각 합니다. 이와 관련해서는 굳이 소통이니 통섭이니 하지 않아도 어느 학문 
분야보다 앞서서 다른 분야와의 교류와 협력의 필요성을 일상적으로 느끼 고, 또 그래서 수시로 교류와 협력이 이루어지는 분야가 고고학계가 아닌가 싶습니다. 이를테면 고고학과 보존과학(보존처리) 분야는 떼어놓고 생각할 수 없을 만큼 밀접합니다. 발굴 현장에는 출토된 유물이 적절한 시점에 적 절한 보존처리나 응급조치가 이루어지지 않으면 치명적인 훼손이 진행되어 유물로서의 가치를 완전히 상실해버릴 개연성이 상존하고 있습니다. 그러니 보존과학(보존처리)의 협력은 선택이 아닌 필수입니다. 또 발굴 결과를 검토 할 때 미술사, 역사학 등 인접 분야의 전문가들이 함께 참여하는 일은 거의 일상처럼 일어납니다. 그러므로 고고학계에 서로 다른 학문 분야 사이의 소 통을 길게 말할 필요는 없을 것입니다. 그렇더라도 혹시 그 소통과 교류와 협력이 더 확대되고 심화되어야 할 필요는 없는지, 충분하다는 방심 때문에 놓치고 있는 부분은 없는지 점검해 볼 여지는 있어 보입니다.

제가 좀 더 관심을 갖는 사항은 고고학 연구자라면 마땅히 갖추어야 할 '교양입니다. 저는 평소 한자문화권에 속하는 지역에서 인문학이나 사회학 을 하는 사람이라면, 더 나아가 학문을 하는 사람이라면 중국을 중심으로 한 동아시아에서 형성된 고전문화, 곧 넓은 의미의 중국문화와 그것을 전달하 는 매체인 고전 한문에 대한 이해는 기본으로 장착하고 있어야 된다고 믿고 있습니다. 적어도 한자문화권에서는 중국문화가 보편문화요, 한자와 한문이 보편언어라고 생각하기 때문입니다. 서양인들에게 라틴어와 그리스- 로마문 화가 보편언어요 보편문화이듯이, 그래서 그들이 라틴어와 그리스·로마문 화를 기본적인 도구요 상식적인 교양으로 갖추고 있듯이 우리도 한자와 한 문, 중국문화에 그러해야 한다고 생각하는 것입니다.

그러나 제가 경험을 통해 알고 있는 우리의 현실은 제 생각과 많이 다릅 니다. 박물관의 책임자로 짧지 않은 기간 일하다 보니 새로 맞이하고 떠나 보낸 직원들의 숫자도 적지 않습니다. 그들은 모두 미술사, 역사학, 고고학, 서지학 등의 분야에서 석사 과정 수료 이상의 자격을 지니고 있었습니다. 
그렇지만 그들 가운데 부족하나마 한문 독해 능력을 보유한 사람은 하나도 없었습니다. 따라서 중국문화에 대한 교양 수준도 보잘 것이 없었습니다. 어 떻게 이런 일이 가능한지 저로서는 참으로 이해하기 어려웠습니다. 학부 과 정은 제쳐두더라도 대학원에서 한문에 대한 소양 없이 자신들의 전공과목을 이수하는 일이 어떻게 가능한지, 교수님들은 그런 학생들을 또 어떻게 지도 할 수 있었는지 궁금하기 짝이 없었습니다. 일반 고고학이든 불교고고학이 든 이와 같은 인력으로 정상적인 활동이 가능하고 유의미한 성과를 거둘 수 있는지 묻지 않을 수 없습니다. 만일 여기에 그렇다고 대답할 수 없다면 관 계자들께서는 그에 대한 대책을 깊이 고민해야만 할 것입니다. 제가 보기에 불교고고학을 염두에 둔 분들이라면 그 길에 들어서는 후학들에게 중국문화 로 대표되는 동아시아의 고전문화와 한문에 대한 소양을 전공을 위한 도구 이자 바탕이며 배경으로 갖추도록 하는 일은 반드시 해결해야 할 선결과제 의 하나가 아닐까 싶습니다.

'불교고고학'을 표방한다고 할 때 불교와 고고학은 어떻게 만나야 바람직 할까, 하는 점도 제게는 궁금증을 불러일으키는 문제의 하나입니다. 원론적 으로 이야기하자면 종교와 학문은 지향하는 바나 기능이 서로 다르기 때문 에 양자가 서로 만날 때 적절한 거리, 우호적인 긴장 관계가 필요하지 않을 까 싶습니다. 제 생각에 불교고고학을 자신의 학문 영역으로 생각하는 분이 라면 불교라는 종교에 대한 이해와 지적 탐구는 깊고 넓을수록 좋을 듯합니 다. 이 점에 대해서는 긴 설명이 필요치 않을 것입니다. 그러나 그것이 꼭 신앙으로까지 연결될 필요는 없다고 생각합니다. 다시 말해 지식으로서의 불교는 불교고고학 종사자에게 필수조건이지만 신앙으로서의 불교는 그렇지 않다는 것입니다. 물론 자신의 종교로, 신앙으로 불교를 선택하는 것도 얼마 든지 있을 수 있고 무방하겠지만, 그럴 때라도 자신의 신앙과 학문을 뒤섞지 않을 최소한의 양식은 기본 전제로 갖추어야 한다고 봅니다.

종교와 학문의 관계에 있어서 오히려 제가 우려하는 것은 교계와 학계의 
관계 설정입니다. 대체로 교계와 학계의 관계에 있어서 전자가 우월한 위치 에 있음은 있는 그대로의 현실입니다. 그럴 때 어떤 사안을 두고 양쪽의 관 점과 입장이 다르다면 그것을 어떻게 정리하는 것이 현명하겠습니까? 구체 적인 예를 들어 발굴이 끝난 어느 절터를 두고 학계에서는 복원의 필요성도 가능성도 없다고 판단하고 있을 때, 교계에서 복원 혹은 복원이 가능한 방안 의 모색을 요구해 온다면 어떻게 해결의 실마리를 풀 수 있겠습니까? 교단 의 사정을 잘 알고 있는 저로서는 이와 비슷한 일들이 얼마든지 빈번하게 일어날 수 있다고 생각합니다. 그런 상황에서 학문적 신념에 배치되는 교계 의 요구나 무리한 압력, 지나친 간섭에 슬기롭게 대처할 수 있는 마음의 준 비는 되어 있고 노하우는 축적되어 있는지 적잖이 걱정스럽습니다. 저는 이 점 또한 관계자 여러분들이 제법 심각하게 고민해 보아야 할 문제라는 생각 을 지울 수 없습니다.

또 한 가지 떠오르는 것은 불교고고학이 학문적 대상으로 삼는 범위는 어 디까지인가 하는 점입니다. 정확한 소견인지는 모르겠습니다만, 제가 알기 에 똑같이 불교고고학을 주창하더라도 한국과 일본은 염두에 두는 대상의 범위가 다른 것 같습니다. 한국측에서는 대체로 연구의 범위를 불교유적과 유구에 한정하는 듯하고, 반면에 일본쪽에서는 그보다 훨씬 범위를 넓혀 발 굴을 통해 드러나는 유적과 유구는 물론 지상에 전해지는 장엄구, 공양구, 의식구 등 거의 모든 불교미술품까지를 망라하여 연구의 범위에 포함시키고 있는 것 같습니다. 편의상 아주 도식적으로 갈라 말하자면 한국쪽은 '땅 아 래의 고고학'에 머물러 있는 반면 일본측은 '땅 위의 고고학'을 지향하는 게 아닌가 싶습니다.

저의 이런 관찰이 그리 어긋나지 않다면, 저는 한국의 관계자분들께 우리 도 연구 대상의 범위를 땅 위까지 확대해 보면 어떨까, 하는 제안을 드리고 싶습니다. 아마도 그러면 불교미술사를 전공하는 분들께서 당혹해 하거나 마뜩찮은 눈길을 보낼 것이 예상됩니다만, 뭐 그러면 어떻습니까? 그 분들만 
불교미술을 전공하란 법도 없고, 무엇보다 미술사학계에서는 기대할 수 없 는 참신한 시각이나 새로운 관점을 제공할 수도 있지 않겠습니까? 동일한 불교미술품을 보더라도 미술사학자와 고고학자는 서 있는 바탕이 다르다 보 니 분명 달리 보는 것들이 있으리라 생각됩니다. 저는 그런 것들이 학계에 자극이 되고 활발한 논쟁을 유도하며 학문적 결과물들을 풍성하게 하는데 기여할 수 있다는 생각이 듭니다. 이런 저의 생각이 물정 모르는 소견이 아 니라면 퍽 다행이겠습니다.

마지막으로 한 가지만 더 말씀드리겠습니다. 국제교류에 관한 것입니다. 아시다시피 한 - 중 - 일 동아시아 삼국은 자국의 역사를 보는 눈, 서로가 서 로의 역사를 보는 눈이 객관적 진실, 역사적 사실과는 다소 동떨어진 것이 사실입니다. 각도가 조금씩 다르기는 하지만 모두들 평범하지 않은 근대를 겪었고, 각기 처한 현대의 정치사회적인 입장을 반영한 선입견이 작용하고 있기 때문입니다. 간단히 말해 상이한 근대의 경험과 오늘의 시각이 투영된 눈으로 과거의 역사를 보고 있는 것입니다.

이럴 때 그렇게 왜곡되고 정당하지 않은 역사인식을 바로잡아 줄 수 있는 아주 유효한 수단의 하나가 물증이 뒷받침된 고고학적 성과라고 저는 생각 합니다. 특히 한일 고대사에 있어서 그런 과정을 통해 우리의 인식 지평을 넓히고 그릇된 사실 관계를 수정한 예를 얼마든지 들 수 있음을 우리는 알 고 있습니다. 그렇다면 이와 같은 성과를 오늘 우리가 논의하고 있는 불교 고고학에 적용해 봄직도 하지 않겠습니까? 사실 그 동안 우리는 자국의 불 교사에 매몰되어 이웃 나라의 불교사에는 눈 돌릴 겨를이 없었던 듯합니다. 모르겠습니만, 특히 고고학계에서는 이 점이 한결 심하지 않았나 싶습니다. 그러니 늦기는 했습니다만 이제라도 불교고고학의 입장에서 이웃 나라의 동 향에 주의를 기울이고 드러난 성과들을 공유한다면 자국의 불교사는 물론 일반 역사 이해의 수준을 한층 높여 나갈 수 있지 않겠나 생각합니다. 부디 오늘 이 자리가 그 출발점이 되기를 빌어 봅니다. 
어렵게 마련된 자리, 귀한 시간에 별 소용에 닿지 않는 이야기를 장황하 게 늘어놓은 것은 아닌지 모르겠습니다. 서두에 말씀드린 것처럼 이미 여러 분들이 알고 있는 사실들이지만 새로이 환기하는 기회라도 되었다면 다행이 겠고, 두서없는 논의 가운데 한두 가지라도 건질 것이 있었다면 정말 고맙겠 습니다. 들어주셔서 감사합니다. 
